\title{
Hemispheric developmental venous anomaly draining into a vein of Galen varix: a case report and literature review
}

\author{
Hangzhe $\mathrm{Xu}^{1}$, Jun Zheng ${ }^{2}$, Gao Chen ${ }^{1}$ and Jingsen Chen ${ }^{1 *}$
}

\begin{abstract}
Background: Developmental venous anomaly (DVA), previously known as "venous angioma", is the most common cerebral vascular malformation, but hemispheric DVA is extremely rare.

Case presentation: In this article we present a 21-year-old female with a large DVA draining the whole left hemisphere, combined with a vein of Galen varix and falcine sinus. To our knowledge, only 4 cases of hemispheric DVA have been reported before, however, none with a vein of Galen varix. This patient's digital subtraction angiography also revealed double straight sinus with severe stenosis of one of the sinuses, which was considered to be the possible reason of the venous varix. The patient was managed conservatively, and her clinical status was stable for 1 year.
\end{abstract}

Conclusions: Because brain DVA drains the normal cerebral parenchyma and the hemorrhage risk is relatively low, hemispheric DVA is considered to be a benign anomaly, and conservative treatment is recommended.

Keywords: Cerebral hemisphere, Developmental venous anomaly, Vein of Galen varix, Venous malformation, Digital subtraction angiography

\section{Background}

Developmental venous anomaly (DVA), also known as "venous angioma" in the past, is the most common cerebral vascular malformation [1]. Most DVAs drain into a dilated collecting vein, and only a few DVAs drain into a cerebral varix [2]. Hemispheric DVA draining into a vein of Galen varix is extremely rare. We present a case of a female with hemispheric DVA draining into a vein of Galen varix and then draining into a falcine sinus; the patient also had double straight sinuses, with severe stenosis of one of them. The imaging features of this patient are presented, and the literature is reviewed. The aim of this case report is to help us further understand the formation of DVA and the process of venous development.

\section{Case presentation}

A 21-year-old female was referred to our department with a diagnosis of cerebrovascular malformation found

\footnotetext{
* Correspondence: furycj@@126.com

${ }^{1}$ Department of Neurosurgery, The Second Affiliated Hospital Zhejiang University School of Medicine, Jiefang Road 88th, Hangzhou, Zhejiang 310016, People's Republic of China

Full list of author information is available at the end of the article
}

by a computerized tomography $(\mathrm{CT})$ scan after a slight head trauma that occurred 8 days prior to the scan. The patient reported slight dizziness, with a sutured wound $(1 \mathrm{~cm})$ at the right forehead. She demonstrated normal growth and development without mental retardation or cognitive-comprehension deficits. She denied any occurrence of syncope, acute-onset headache, or migraine, except a history of asphyxia when born. CT angiography and contrast-enhanced cerebral magnetic resonance imaging showed an enhanced circular lesion $(2 \mathrm{~cm}$ in diameter) in the quadrigeminal cistern, and a typical "caput medusa" appearance could be observed clearly in the whole left hemisphere (Figs. 1 and 2). A left orbital hemangioma could also be diagnosed based on CT and magnetic resonance imaging (MRI) (not shown in the picture). No hydrocephalus was found.

The patient underwent digital subtraction angiography (DSA) soon after she came to our department, and the result was noteworthy. The arterial phase of both right and left carotid artery and vertebral arteriograms were normal. The venous phase of the left carotid artery showed a deep-type large DVA draining the entire left hemisphere. The majority of the DVA was draining into 

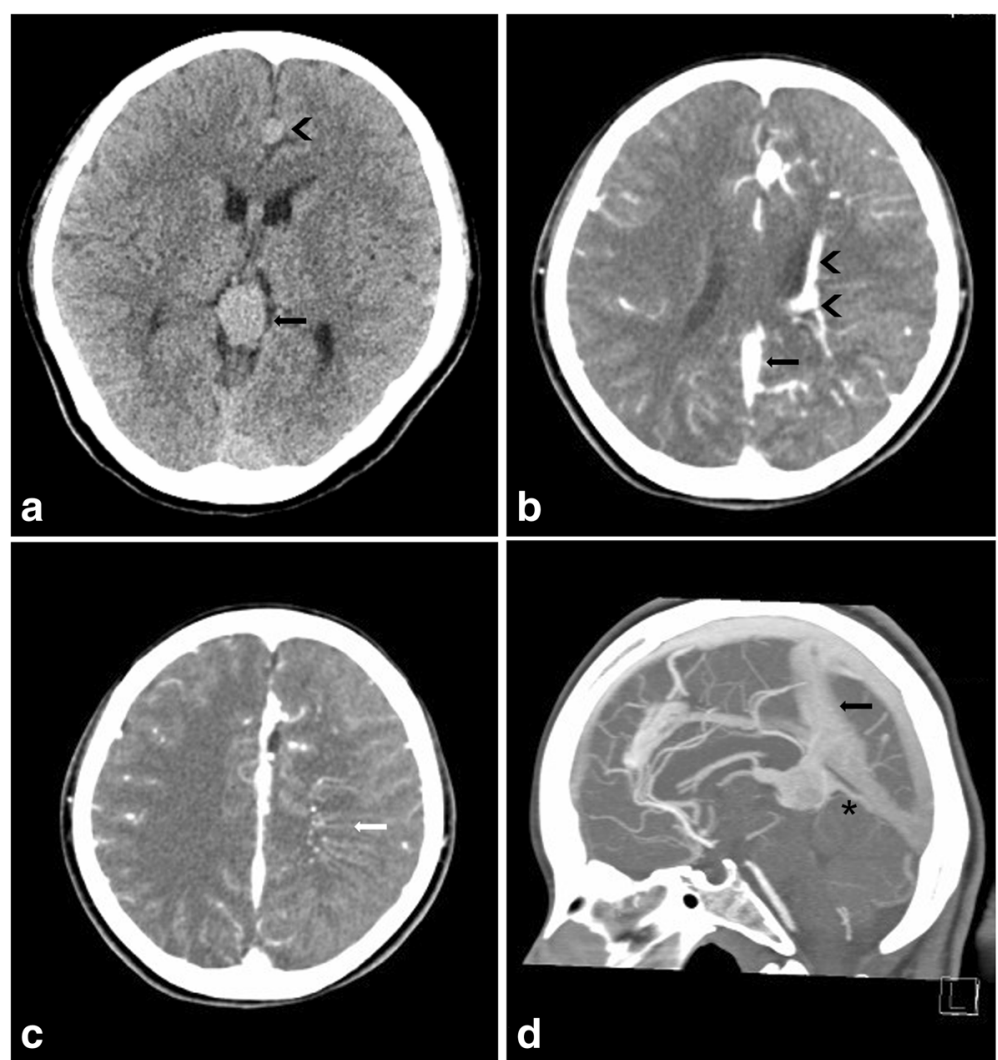

Fig. 1 Axial CT (a) showed a high-density circular lesion ( $2 \mathrm{~cm}$ in diameter, black arrow) in the quadrigeminal cistern. The dilated inferior sagittal sinus (arrow head) could also be observed. Axial CT angiography (CTA) images (b, c) showed a present falcine sinus (black arrow), a "caput medusae" (white arrow) and a collecting vein beside the lateral ventricle (arrow head). In the sagittal CTA image (d), the present falcine sinus (black arrow) and the vein of Galen varix are clearly visualized. The double straight sinus can be observed, and the inferior one can be found with stenosis (*)

a dilated vein of Galen via a varicose collecting vein. Part of the DVA was draining into the bilateral internal cerebral veins (ICVs), which made the veins mildly dilated. The vein of Galen varix converged with the inferior sagittal sinus and then entered into a falcine sinus as well as two straight sinuses. The inferior sinus seemed to be severely stenotic. The left Labbe's vein was also affected and dilated and drained into the left transverse sinus.
Part of the superior and inferior sagittal sinuses, torcular herophili, and left transverse sinus were dilated (Fig. 3). There was no evidence of AVM or AVF in the DSA of this patient, which was judged to favor a final diagnosis of hemispheric DVA draining into a vein of Galen varix rather than a typical vein of Galen aneurysmal malformation (VGAM). As her symptom was only nonspecific mild dizziness probably caused by head trauma with no

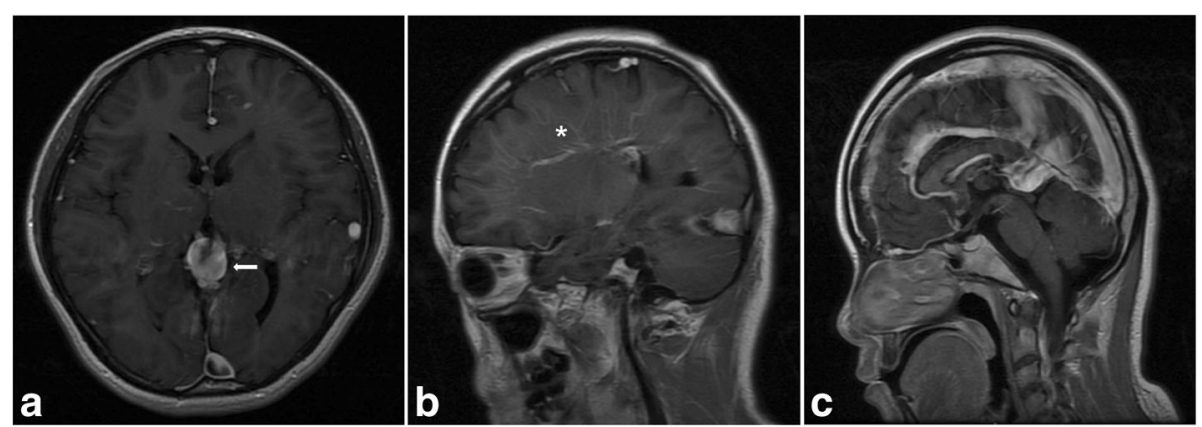

Fig. 2 Axial T1-weighted contrast-enhanced MR image (a) showed a markedly dilated vein of Galen (white arrow), left Labbe's vein and superior sagittal sinus. Sagittal T1-weighted contrast-enhanced MR images $(\mathbf{b}, \mathbf{c})$ demonstrating the typical "caput medusae" appearance of the whole left hemisphere $\left(^{*}\right)$ and a dilated duro-venous system 


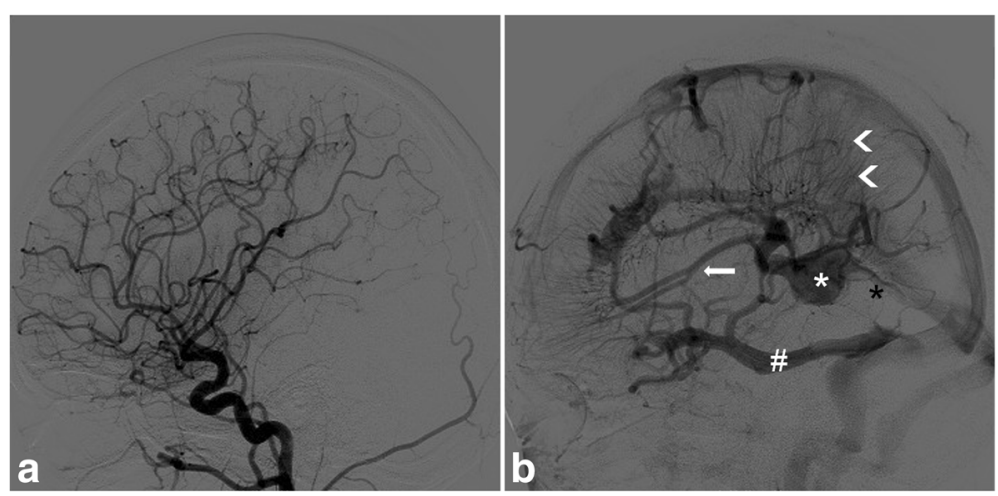

Fig. 3 Digital subtraction angiogram of the arterial phase of the left carotid artery (a) demonstrated normal findings. During the venous phase of the left carotid artery (b), the hemispheric venous anomaly, dilated ICVs (white arrow), left Labbe's vein (\#), present falcine sinus (arrow head), and vein of Galen varix (white *) are clearly visualized. The double straight sinus can be observed, and the inferior one can be found with stenosis (black *)

evidence of hydrocephalus, intracranial mass effect or thrombosis, we decided to monitor her in the outpatient setting instead of an urgent intervention, and her clinical status was stable for 1 year.

\section{Discussion}

Developmental venous anomaly, first suggested by Lasjaunias [3] in 1986, used to be known as "venous angioma" or "cerebral venous malformation". It consists of a radial complex of venous radicles, named "caput medusae" in angiographies, and a dilated collecting vein, which drains the normal cerebral parenchyma. The imaging features and differential diagnosis of DVAs were previously described [4]. DVAs of the brain range from a small draining vein, involving a small portion of the brain, to a large hemispheric venous anomaly [1], and the latter is extremely rare. To our knowledge, there are only 4 reported cases of an entire hemispheric DVA, such as in this case [4-7] (Table 1). The clinical symptoms include dizziness ( 1 case), headache (1 case) and epilepsy ( 2 cases). Two of them presented with an enlargement of the vein of Galen $[5,6]$, but none presented with involvement of the vein of Galen varix or a falcine sinus as in the current patient. Two of them combined with cerebral hemiatrophy of the anomalous hemisphere [5, 7], which was considered to be caused by longstanding venous congestion [5] and which was not found in our patient. All these patients were managed conservatively.

Venous varix, as Lasjaunias described in the 1980s, "does not exist without an obstruction in the cerebral venous system, and the location varies from the proximal straight sinus to the jugular foramen" [3]. However, as an increasing number of cases are currently being described, "venous hypertension" is becoming the new cause of these types of anomalies. In the cases without collecting vein stenosis, venous hypertension may also exist because of volume overload as the result of histopathological changes in the vessel wall, including wall thickening and hyalinization [1]. In this case, stenosis of the inferior straight sinus is considered to be the reason for vein of Galen varix. To compensate for the increased pressure of the venous system, the falcine sinus did not close, and another straight sinus occurred, as well as a vein of Galen varix and a dilated duro-venous system. The key point in the differential diagnosis of vein of Galen varix from a true vein of Galen aneurysmal malformation (VGAM) was the absence of arteriovenous malformation (AVM) or arteriovenous fistula (AVF).

As this special system drained the normal cerebral parenchyma, these changes are considered to be a "venous anomaly" and not a "venous malformation". As the hemorrhage risk of DVA is very low (the retrospective

Table 1 Summary of the literature on patients with hemispheric developmental venous anomaly

\begin{tabular}{|c|c|c|c|c|c|c|}
\hline Authors/Year & Sex/Age (years) & Site of the DVA & Presenting features & Diagnosing methods & Imaging features & Follow-up \\
\hline Aagaard, 1999 [4] & M/33 & Right & $\begin{array}{l}\text { Seizures, Hemangiomas } \\
\text { throughout the face }\end{array}$ & MRI, DSA & $\begin{array}{l}\text { Enlargement of VG, straight sinus } \\
\text { and torcular herophili }\end{array}$ & NR \\
\hline Uchino, 2001 [5] & $M / 48$ & Right & Dizziness & MRI, DSA & $\begin{array}{l}\text { Cerebral hemiatrophy, hypoplastic } \\
\text { straight sinus }\end{array}$ & 2 years \\
\hline Casey, 2011 [6] & $M / 12$ & Right & Headache & MRI & $\begin{array}{l}\text { Tortuous draining vein terminating } \\
\text { in straight sinus }\end{array}$ & NR \\
\hline Jung, 2013 [7] & $F / 33$ & Left & Epilepsy & MRI & Skull atrophy & NR \\
\hline
\end{tabular}

DSA digital subtraction angiography, $F$ female, $M$ male, $M R I$ magnetic resonance imaging, $N R$ not reported, $V G$ vein of Galen 
risk is $0.22 \%$ per year [8], and the prospective risk is $0.68 \%$ per year [9]), and an inappropriate surgical or interventional therapy may cause a horrible consequence, conservative treatment is recommended for patients with endurable clinical symptoms.

\section{Conclusion}

Hemispheric developmental venous anomaly is an extreme type of DVA that drains the blood of the entire hemisphere, and it tends to combine with nonspecific clinical symptoms such as headache or dizziness. In this report, we presented the imaging results of a special case of hemispheric DVA combined with a vein of Galen varix. The hemorrhagic risk is relatively low, which made it a benign anomaly, and conservative management is recommended.

\section{Abbreviations}

AVF: Arteriovenous fistula; AVM: Arteriovenous malformation; $C T$ : Computerized tomography; DSA: Digital subtraction angiography; DVA: Developmental venous anomaly; F: Female; ICV: Internal cerebral vein; M: Male; MRI: Magnetic resonance imaging; VG: Vein of galen; VGAM: Vein of galen aneurysmal malformation

\section{Funding}

Not Applicable.

\section{Availability of data and materials}

Not applicable.

\section{Authors' contributions}

HX has evaluated the patient, and drafted and revised the manuscript. JZ evaluated the patient, carried out the literature review. GC conceived of the study, and helped to draft the manuscript. JC Collected data and carried out the follow-up. All authors read and approved the final manuscript.

\section{Competing interests}

The authors declare that they have no competing interests.

\section{Consent for publication}

We obtained written permission from the patient to publish this case report.

\section{Ethics approval and consent to participate}

Not applicable.

\begin{abstract}
Author details
${ }^{1}$ Department of Neurosurgery, The Second Affiliated Hospital Zhejiang University School of Medicine, Jiefang Road 88th, Hangzhou, Zhejiang 310016, People's Republic of China. ${ }^{2}$ Department of Neurosurgery, The Second People's Hospital of Quzhou City, Xinan Road 338th, Quzhou, Zhejiang 324022, People's Republic of China.
\end{abstract}

Received: 26 May 2016 Accepted: 8 December 2016

Published online: 06 March 2017

\section{References}

1. Pearl M, Gregg L, Gandhi D. Cerebral venous development in relation to developmental venous anomalies and Vein of Galen aneurysmal malformations. Semin Ultrasound CT MR. 2011:32(3):252-63.

2. Kars HZ, Simsek S, Keskin T. Thalamic venous angiomas draining into a vein of Galen varix. Case illustration. J Neurosurg. 2000:93(6):1083.

3. Lasjaunias P, Burrows P, Planet C. Developmental venous anomalies (DVA): the so-called venous angioma. Neurosurg Rev. 1986;9(3):233-42.

4. Casey MA, Lahoti S, Gordhan A. Pediatric holohemispheric developmental venous anomaly: definitive characterization by 3D susceptibility weighted magnetic resonance angiography. J Radiol Case Rep. 2011;5(5):10-8.
5. Uchino A, Sawada A, Takase Y, Abe M, Kudo S. Cerebral hemiatrophy caused by multiple developmental venous anomalies involving nearly the entire cerebral hemisphere. Clin Imaging. 2001;25(2):82-5.

6. Aagaard BD, Song JK, Eskridge JM, Mayberg MR. Complex right hemisphere developmental venous anomaly associated with multiple facial hemangiomas. Case report. J Neurosurg. 1999;90(4):766-9.

7. Jung AK, Henson JW, Susanto D, Caylor LM, Doherty MJ. Holohemispheric developmental venous anomaly. Neurology. 2013;80(18):1718-9.

8. Garner TB, Curling OD, Kelly DL, Laster DW. The natural history of intracranial venous angiomas. J Neurosurg. 1991;75(5):715-22.

9. McLaughlin MR, Kondziolka D, Flickinger JC, Lunsford S, Lunsford LD. The prospective natural history of cerebral venous malformations. Neurosurgery. 1998;43(2):195-200. discussion 200-1.
Submit your next manuscript to BioMed Central and we will help you at every step:

- We accept pre-submission inquiries

- Our selector tool helps you to find the most relevant journal

- We provide round the clock customer support

- Convenient online submission

- Thorough peer review

- Inclusion in PubMed and all major indexing services

- Maximum visibility for your research

Submit your manuscript at www biomedcentral.com/submit
BioMed Central 